\title{
Evaluating tradeoffs among ecosystem services to inform marine spatial planning
}

\author{
Sarah E. Lester ${ }^{\mathrm{a}, \mathrm{b}, *}$, Christopher Costello ${ }^{\mathrm{b}}$, Benjamin S. Halpern ${ }^{\mathrm{c}}$, Steven D. Gaines ${ }^{\mathrm{b}}$, Crow White ${ }^{\mathrm{b}}$, \\ John A. Barth ${ }^{\mathrm{d}}$ \\ a Marine Science Institute, University of California, Santa Barbara, CA 93106-6150 USA \\ b Bren School of Environmental Science \& Management, 2400 Bren Hall, University of California, Santa Barbara, CA 93106-5131, USA \\ ${ }^{\mathrm{c}}$ National Center for Ecological Analysis and Synthesis, 735 State Street, Suite 300, Santa Barbara, CA 93101, USA \\ ${ }^{\mathrm{d}}$ College of Oceanic \&' Atmospheric Sciences, Oregon State University, 104 COAS Admin Building, Corvallis, OR 97331, USA
}

\begin{abstract}
A B S T R A C T
A central challenge for natural resource management is developing rigorous yet practical approaches for balancing the costs and benefits of diverse human uses of ecosystems. Economic theory has a long history of evaluating tradeoffs in returns from different assets to identify optimal investment strategies. There has been recent progress applying this framework to the delivery of ecosystem services in land use planning. However, despite growing national and international interest in marine spatial planning, there is a lack of parallel frameworks in the marine realm. This paper reviews an ecosystem service tradeoff analysis framework and provides a more comprehensive synthesis for how it can be applied to marine spatial planning and marine ecosystem-based management. A tradeoff analysis approach can reveal inferior management options, demonstrate the benefits of comprehensive planning for multiple, interacting services over managing single services, and identify 'compatible' services that provide winwin management options.
\end{abstract}

\section{Introduction}

Given the scope and magnitude of the environmental challenges facing natural resource management, there is an increasing demand for more holistic, ecosystem-based approaches to management [1-4]. Ecosystem-based management (EBM) is a placebased approach that aims to achieve the long-term ecosystem health and functioning that in turn provide the ecosystem services on which people rely [4-8]. Marine spatial planning (MSP) is one type of planning process that offers a promising opportunity for more integrated management and has been gaining political momentum throughout the world $[9,10]$. MSP identifies which areas of the ocean are appropriate for different uses or activities in order to reduce conflicts and achieve ecological, economic and social objectives [11]. One central challenge for translating EBM and MSP tenets from concept to practice is

\footnotetext{
* Corresponding author at: Marine Science Institute and Bren School of Environmental Science \& Management, University of California, Santa Barbara, CA 93106-6150, USA

Tel.: +1 805893 5175; fax: +18058938062

E-mail addresses: lester@msi.ucsb.edu (S.E. Lester), costello@bren.ucsb.edu (C. Costello), halpern@nceas.ucsb.edu (B.S. Halpern), gaines@bren.ucsb.edu (S.D. Gaines), cwhite@bren.ucsb.edu (C. White), barth@coas.oregonstate.edu (J.A. Barth).
}

developing rigorous and straightforward approaches for balancing diverse human uses of ecosystems [12]. This paper highlights tools from economic theory and multi-objective decision making for evaluating tradeoffs in the delivery of ecosystem services, with particular emphasis on how such an approach could transform ocean management.

Ecosystem services range from tangible to intangible (e.g., food production versus aesthetic value) and provide natural capital that is essential to human welfare [13]. The Millennium Ecosystem Assessment [1] brought ecosystem service concepts to the forefront, developing four widely used service categories: provisioning (e.g., of seafood, timber), regulating (e.g., of climate, floods, water quality), supporting (of other services, e.g., pollination for food production, nutrient cycling), and cultural (e.g., recreation, spiritual value). MSP attempts to allocate space to the full range of services provided by the oceans, presenting a significant challenge to natural resource managers. Services frequently are not independent of one another, but instead exhibit complex interactions that generate tradeoffs in the delivery of one service relative to the delivery of others [14-17]. In some cases, two services may be mutually exclusive in space (e.g., wave energy buoys may preclude commercial fishing and vice versa), while in other cases the tradeoff is less severe (e.g., fishing and recreational activities can often occur in the same locations, but 
fishing impacts might have a negative effect on some types of recreation). Because not all interacting services can be maximized simultaneously, society must make decisions about their relative preferences for different services, and, consequently, how this affects management decisions [15,18-20]. Managers make these types of decisions on a regular basis, but often do so without the explicit consideration of these tradeoffs [21].

Balancing the delivery of a range of services is particularly critical for coastal and ocean ecosystems, which face growing human populations, increasing associated impacts, and declining ecosystem services [22-24]. Marine systems offer a challenging and interesting opportunity for implementing MSP and specifically for examining tradeoffs among services. For one, service valuation in marine settings is complicated given the general absence of property rights and the related fact that many key services are not traded in markets (e.g., recreation, wildlife viewing, protection from shoreline erosion). Furthermore, the primary market service from the oceans fisheries - often lacks property rights, has inappropriate incentives and frequently ineffective governance, and is managed using limited-quality stock assessments, which together promote unsustainable fishing $[25,26]$. Management in the oceans also tends to be fragmented, with limited governance or institutional frameworks for spatial management and coordinated management across sectors $[27,28]$. Lastly, marine systems host numerous emerging uses, such as wave energy and offshore aquaculture. These emerging uses will contribute to crowding among efforts to maximize the delivery of particular services, posing an ideal prospect for more integrated planning prior to their development. Such planning demands an explicit analysis of tradeoffs among services under different management scenarios.

The economics discipline has developed a rich "production theory" which concerns how firms optimally trade-off between different inputs to production [29]. This is similar to portfolio theory, which analyzes the tradeoff between variance (i.e., risk) and return of a collection of assets, whether financial stocks or fish stocks, so as to maximize return for a given level of risk [30-32]. In parallel, there is a long history within decision theory, including multi-criteria and multi-objective analyses, of developing tools for decision-making where there are numerous and often competing objectives [33]. Multi-criteria analysis has been applied to numerous marine applications [34-37] and there has been recent progress applying these ideas to managing ecosystem services [20,38-41]. However, there is not a synthesis of how tradeoff analysis can used in an EBM or MSP approach. This paper (1) highlights one framework for analyzing tradeoffs, including reviewing the types of tradeoffs possible in an ecosystem services context and examining how this framework can guide EBM and (2) provides demonstrations of how ecosystem service tradeoff analysis can be applied to MSP using two stylized examples based on data.

\section{Conceptual framework for ecosystem service tradeoff analysis}

Production theory, a branch of microeconomics that deals with the production (as opposed to the consumption) side of the economy, was developed to examine marketed commodities [42]. While not a perfect parallel, this approach can also be applied to the production of ecosystem services, marketed or otherwise [43]. The guiding principle when applied to EBM is to ensure the sustainable and efficient delivery of multiple interacting services. The challenge in meeting this goal is that providing ecosystem services is "costly" in the sense that actions taken to deliver one service may inhibit or divert scarce resources away from actions that could have been taken to deliver other services. For example, if one is using marine reserves to provide the ecosystem service of biodiversity preservation, the possible provision of fishery yield is reduced as a second service. The cost of lost provisions from one service due to the use of another service depends on the strength and nature of their interaction. Not all services produce 'costs' to other services and this framework allows one to identify 'compatible' services as well. In short, the following analytical approach supports more informed management decisions about real and perceived tradeoffs among ecosystem services.

Production theory considers how different inputs produce different levels of outputs, typically expressed as production functions. When applied to ecosystem services, production functions are models that translate the structure and functioning of ecosystems into the provision of ecosystem services $[40,44,45]$. A production function approach has been used to value non-market ecosystem services that can be considered as inputs into the production of goods or services with market value (e.g., seagrass habitat as nursery grounds is an input into fisheries) [43,46], but also applies to ecosystem services that are not readily connected to a marketed output. Importantly, there may be many potential ecosystem service outcomes that can arise from a given set of inputs. This provides a basis for examining which outcomes are optimal in terms of providing the combination of services that are important to society.

In cases with a small number of services or objectives, ecosystem service outcomes can be analyzed graphically to evaluate tradeoffs. In an EBM context, this involves some quantification of the ecosystem services produced across a broad range of potential management actions or spatial plans (e.g., all possible MPA siting options, all possible harvest regulations, etc.). This can be conducted using empirical data, quantitative models or conceptual models, depending on data and model availability, and ideally considers as many sets of management actions as possible. In such an analysis, the axes of the graph correspond with levels of ecosystem services and each point corresponds with the outcomes from a given set of management actions that are known or estimated to produce amounts of each service. After plotting all (or a large subset of) possible management options, the constraint envelope, or outer bound of all the points, is the "efficiency frontier" comprised of Pareto-efficient options, whereby one service cannot be further increased without a cost in terms of the other service (Box 1). This "ecosystem services" frontier depicts management options that provide for the optimal delivery of the two or more services $[37,47,48]$. Points interior to the frontier are suboptimal-at least one service could be increased, at no cost to other services.

Although this approach may seem simplistic, it provides two critical insights that can be used to guide EBM. First, the position of a point relative to the frontier can suggest improvements to current management practices. Regardless of the shape of the frontier or social preferences for specific services, all sets of management actions interior to the frontier represent suboptimal decisions. These are situations where an EBM approach can lead to societal benefits at no extra cost, and commonly a gain, for both services. Such knowledge therefore has the potential to eliminate some conflicts among user groups, as it allows clearly inferior management decisions to be objectively eliminated. Of particular interest are situations in which management options that are all interior to the frontier are being debated. In such cases of "false tradeoffs", these options may be unnecessarily pitted against each other, and tradeoff analysis could illustrate that additional management options exist that simultaneously remove the perceived tradeoff and produce a win-win outcome.

Second, the relationship between or among services also indicates whether coordinated management across services is necessary. In other words, the shape of the frontier can inform what the optimal management solution(s) is likely to be, narrowing the scope of potential policy options. Examining pairwise 
Box 1-Common types of ecosystem service interactions: insights gained from frontier shapes. Although the focus here is on pairs of services, management decisions will undoubtedly influence multiple services simultaneously. The logic for thinking about the frontier with multiple services, however, is the same, although it is difficult to visualize more dimensions.

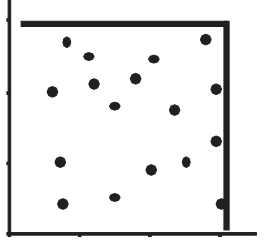

Non-interacting services: These services can be managed independently (e.g., two non-interacting fisheries species with non overlapping habitat requirements). The optimal management solution is at the vertex of the two lines. This type of relationship does not typically arise from traditional economic theory.

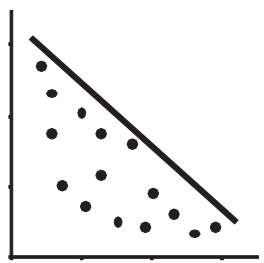

Direct tradeoff: A management decision that increases the provisioning of one service results in a proportional decrease of the other service, with no diminishing returns, and vice versa (e.g., zoning mutually exclusive uses of areas of the ocean). This is a common expectation of how services trade off with each other, although it is likely uncommon for most ecosystem services.

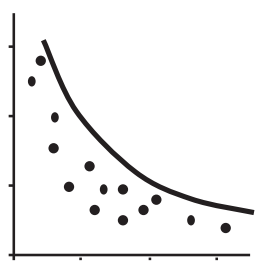

Convex tradeoff: Obtaining even a small increase in the provisioning of one service comes at a large cost for the other service. Scenarios near the middle of the frontier are optimal only when societal preferences for the two services are equal or nearly so. Asymmetrical preferences force management decisions toward "corner solutions" where one of the services is zero (Fig. 1). As a result, stakeholder conflicts are more likely because there is little middle ground for compromise.

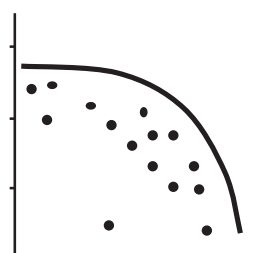

Concave tradeoff: Although there is a tradeoff, there are scenarios that increase the delivery of one service substantially without a large cost to the other service (e.g., if MPAs produce significant spillover of targeted fish, they may provide conservation benefits with minimal cost to the fishery). Optimal management solutions for all types of concave curves occur between the horizontal and vertical tangents to the curve and corner solutions (where one service is zero) are unlikely because they would reflect an extreme societal preference for one service over the other. Management is likely to seek a combination of the two services (Fig. 1).

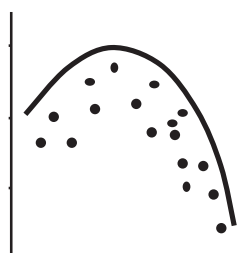

Non-monotonic concave tradeoff: There are some levels of one service for which there are two potential outcomes for the other service. There may be a synergism in the system (e.g., as the yield of a predator species increases, the yield of its prey can also increase because it is released from natural predation). It is sub-optimal to make a decision to the left of the peak of the curve, even in cases where the service on the $y$-axis is valued infinitely more than the service on the $x$-axis.

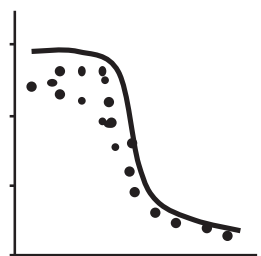

Backwards S tradeoff: Over some range of one service, it can be increased at no cost to the other service. However, after a threshold it becomes very costly to increase that service in terms of the other. This could result from the placement of ocean wind farms and a fishery. If the wind turbines exclude fishing or alter habitat, they could impose costs on the fishery. The costs could initially be small if they are placed in locations with strong winds and poor fishing grounds. Once these "low cost" sites are filled, however, obtaining more wind energy will come at great expense to the fishery.

service interactions, important rules of thumb and insights emerge (Box 1). There are likely other variants on these curves, but this set captures the most common (or at least the most expected) types of relationships. Furthermore, the societal preference for one service compared with another, represented by an indifference curve, will determine which point along the frontier maximizes social value of ecosystem services [42]. Knowing both the shape of the frontier and at least some approximation of the indifference curve allows managers to hone in on a single or small number of optimal management decisions (Fig. 1). Admittedly, societal preferences are typically quite difficult to quantify, and preferences can vary dramatically across segments of society.
There are numerous examples in the terrestrial literature of applying ecosystem service tradeoff analysis to decision-making. As one example, Nalle et al. [49] examine a three dimensional tradeoff for timber production and conservation of two wildlife species using a spatially explicit, dynamic model. They identify optimal land management decisions, the shortcomings of current management practices, and the nature of the tradeoff among the three goals. Polasky et al. [48] examine the tradeoff between biodiversity conservation (number of species) and economic return from different types of land use. This spatially explicit analysis demonstrates the potential for large improvements along both axes by altering current spatial patterns of land use and that 


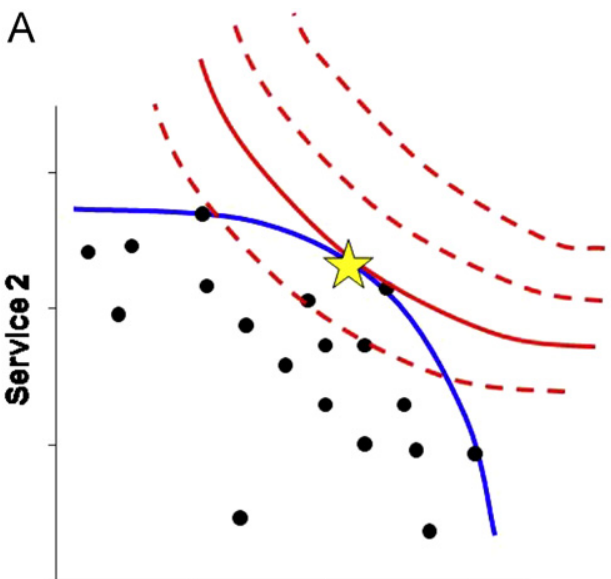

Service 1

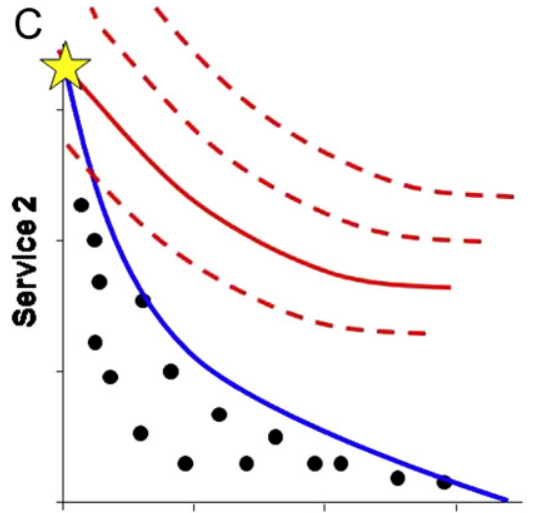

Service 1
B

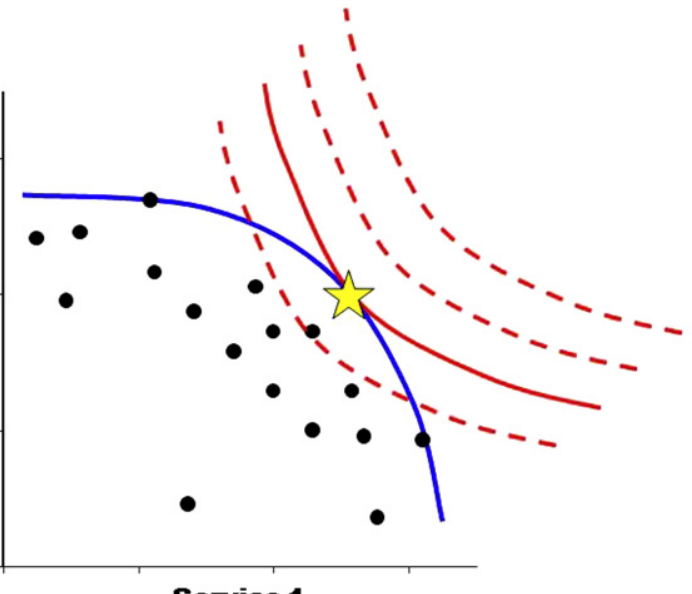

Service 1

D

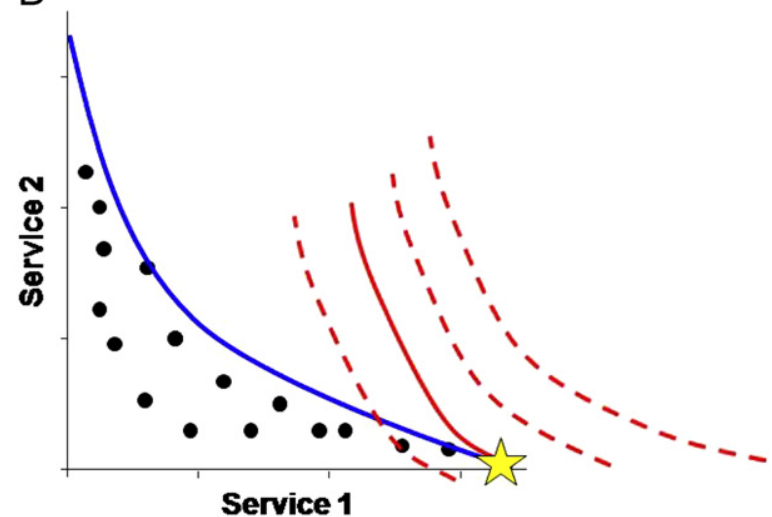

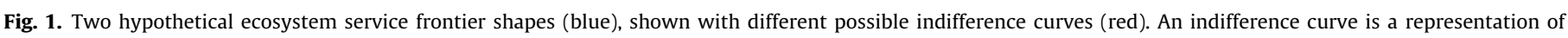

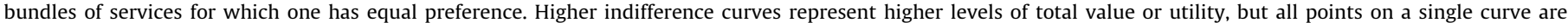

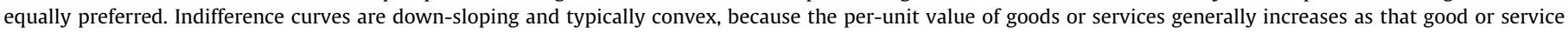

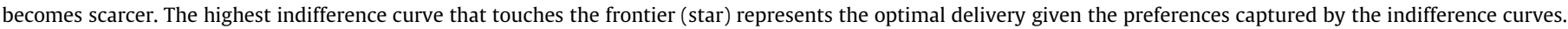

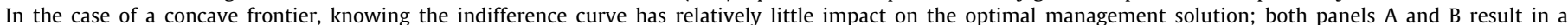

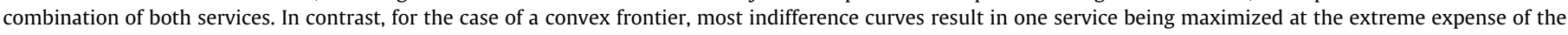

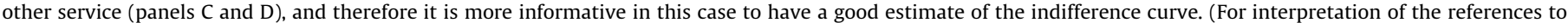
color in this figure caption, the reader is referred to the web version of this article.)

optimal land management options fall along a concave frontier. As another example, Wossink and Swinton [50] examine tradeoffs between agriculture production and the provision of non-market services such as pollination. They theoretically explore the potential for non-monotonic concave frontiers, whereby, for example, crop output and pollination service can have a complimentary or competitive relationship over different levels of pollination output.

Production theory can also be used to examine service tradeoffs without employing graphical analysis. For example, Naidoo and Ricketts [51] conduct a cost-benefit analysis for forest conservation in Paraguay, examining the benefits in terms of five ecosystem services, relative to opportunity costs. Their approach compared maps of different spatial planning decisions, informing what spatial configurations of conservation measures yielded the highest benefits relative to costs. All of these examples illustrate how tradeoff analysis can be applied to natural resource management, but these in-depth case studies lack a more general framework. Box 1 is intended to provide a synthesis of ecosystem service tradeoff theory that will enable more widespread adoption of the approach.

\section{Ecosystem service tradeoff analysis for the oceans}

As demonstrated thus far, the fundamental economic theory behind tradeoff analysis is well developed and applicable to any ecosystem type. However, marine systems offer a particularly challenging prospect for examining tradeoffs among services. Oceans are facing an ever increasing number of human uses and threats, while also typically plagued by fragmented governance. However, MSP offers a promising opportunity for more integrated and ecosystem-based management of multiple services, provided there are the scientific approaches to support such integrated decision making. Two hypothetical case studies grounded in data are presented here, suggesting how tradeoff analysis can advance marine resource management. These examples are intended to catalyze future applications of tradeoff analysis within MSP processes.

\subsection{Case study: fishery yield and biomass preservation}

Fisheries over-exploitation is widely regarded as the primary cause of recently publicized fisheries collapses [23,52]. One suggested approach for conserving fish stocks and marine biodiversity is to create marine protected areas in which all fishing is prohibited, also known as no-take marine reserves [53-56]. Indeed, marine protected areas are typically one of the spatial designations identified in MSP and ocean zoning plans [57,58]. Although marine reserves eliminate fishing within their boundaries, fisheries management outside the reserves can have significant effects on the performance of the reserve, and on the 
ultimate system-wide biomass. For example, for species with considerable adult movement or larval dispersal, small (or sparsely located) marine reserves may not protect stocks if fishing pressure is sufficiently high outside $[59,60]$. Furthermore, although it is intuitive that fishery closures reduce profit from fishing, a less intuitive but powerful recent finding is that fisheries profits can be maintained or even enhanced, for some species, by the tactical siting of marine reserve networks that take advantage of adult spillover and larval export [61-65]. Thus, the size, proximity, and locations of marine reserves will interact in complex ways with fish growth, production, and dispersal, as well as with spatially distinct fisheries exploitation, to influence two common management objectives: fish conservation and profitable fisheries.

To evaluate the tradeoff between biomass conservation (fish biomass remaining in the sea) and sustainable fishery profit, a spatially heterogeneous model of fish production, dispersal, harvest, and profits is used, building on Costello and Polasky [62]. This model is illustrative, and is not intended to replicate any particular geographic region. However, to maintain some level of realism, it is loosely parameterized based on data from the central coast region of California. The model contains a set of 48 distinct patches, each with its own adult survival, larval production, and dispersal to other patches. Spatial heterogeneity enters in two ways. First, larval dispersal depends on ocean currents [66], which are non-uniform in the study system. Second, patch-level adult survival depends on local habitat. In this case, the model focuses on a species associated with kelp, e.g., kelp bass. In the model, higher kelp density in a patch leads to higher adult survival, and density dependence entered through a Beverton-Holt stock recruitment relationship [67]. The full suite of model parameters for each of the 48 patches is available from the authors upon request.

Spatial harvest interacts with abundance (assuming intracohort density-dependence) to affect fish production. Thus, any given spatial harvest strategy (e.g., constant patch-level harvest; heterogeneous harvest across space to maximize steady state profit; set harvest to 0 in some subset of patches to effectively designate these patches as marine reserves) gives rise to an equilibrium fish abundance (in each of $N$ patches), and an equilibrium fishery profit. System-wide fishery profit is the sum of patch-level profit. Profit in a patch is price (scaled to 1) multiplied by harvest minus harvest cost, where harvest cost includes a small "stock effect", as in White et al. [61]. Data on kelp abundance, bottom type, and dispersal characteristics, obtained from the Marine Life Protection Act Initiative (http://www.mar inemap.org/mlpa/), are overlaid on the model domain. The larval dispersal matrix is derived from a Regional Ocean Modeling System [68] oceanographic circulation model [69], assuming a pelagic larval duration of 26-36 days; larvae that reach patches with suitable habitat at the conclusion of the larval period recruit into the adult population. Adults are assumed to have a sufficiently small home range to be considered sessile.

The model is first run simulating 300 harvest policies. Each simulated policy is generated by randomly designing a marine reserve network among the 48 patches (i.e., by closing different sets of patches to fishing) and optimizing exploitation of the fishery in each patch outside of the reserve network. The objective to be maximized (by choosing spatial harvest in each patch outside the reserve) is the weighted sum of fishery profit and biomass, in steady state. The simulated harvest policies randomize the weights within this objective. Equilibrium profit is plotted against equilibrium fish biomass remaining in the sea, with any given harvest strategy representing a point on the tradeoff graph (Fig. 2). All points are scaled relative to the maximum profit and maximum biomass, so the theoretical maximum joint production is $(1,1)$. Second, the frontier is calculated by optimizing the weighted objective specified above, but by leaving the marine reserve network unconstrained (i.e., optimizing fishing pressure in every single patch). The weights in the objective function are altered to trace out the frontier. Lastly, a simulation was run in which fishing pressure is constant across all

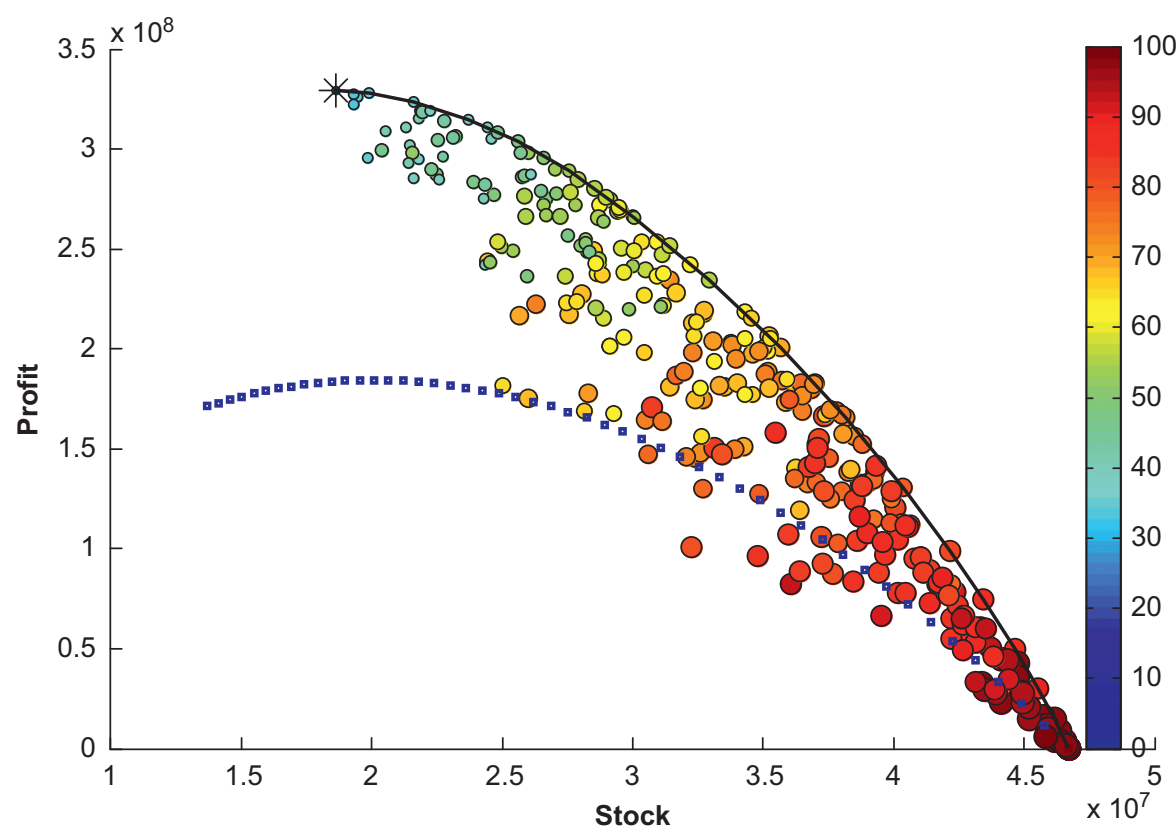

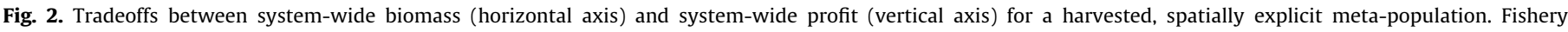

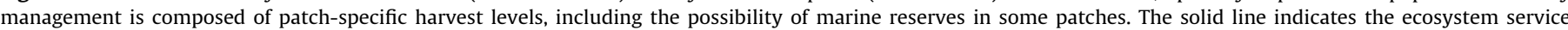

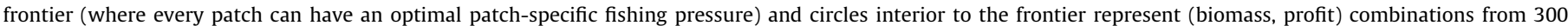

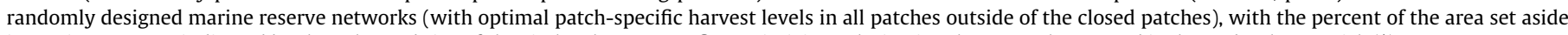

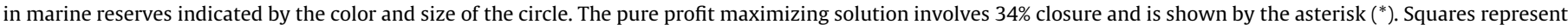
scenarios in which all patches have the same fishing mortality rate, ranging from zero (square furthest to the right) to 0.25 (square furthest to the left). 
patches, ranging from 0 in all patches (100\% no-take areas) to a fishing mortality rate of 0.25 in all patches.

In this example, the frontier is concave, indicating that it is possible to increase the delivery of one service substantially without a large cost for the other service, and that corner solutions (where one service is zero) would only be chosen if there exists extreme societal preference for one service over the other (Fig. 2). Instead, management is likely to seek a combination of conservation and fishery profits. The potential role of marine reserves in obtaining this combination of services can be explored by examining the percentage of the study area set aside in reserves (if any) for management actions that lie along the efficiency frontier. In this example, all harvest policies along the efficiency frontier include at least some patches with zero fishing pressure (marine reserves), with many including a significant percent of the area set aside as no-take areas. This suggests that protected areas not only contribute to conservation but are also an important component of an economically profitable management scenario. Even the policy that maximizes profit without explicit regard for system biomass (“*” in Fig. 2) contains 34\% of the area in marine reserves. Furthermore, when reserves are prohibited by forcing all patches to have the same fishing pressure (Fig. 2, squares), profits are always lower (by as much as $44 \%$ ) compared to the scenario in which reserves are allowed and fishing pressure is patchy across space. This is consistent with a more sophisticated modeling study examining the value of spatially optimized management [70]. These results, if they hold more generally, have the potential to help minimize disputes between conservation and fisheries interests and highlight marine reserves as a key component of marine spatial plans.

\subsection{Case study: wave energy, fishery yield and real estate value}

Rising fuel costs and concerns about the negative impacts of climate change have led to an increased interest in renewable, zero-emissions energy sources (e.g. [71,72]). As a result, wind, wave and tidal power harnessed from coastal areas are being widely considered and implemented around the world. However, in many cases there is not an adequate understanding of the ecological and environmental consequences of these new technologies, or how they may interact - positively or negatively with other services [73-75]. This is true of wave energy, which is being actively considered for many coastal regions [76], including the Oregon coast in the US and Spain and Portugal in the EU $[77,78]$. As an emerging service, wave energy offers the opportunity to apply the ecosystem service tradeoff analysis proactively, using it as a tool to inform the spatial siting of wave energy facilities in a manner that minimizes conflicts among multiple ocean uses.

In this case example, siting of wave energy conversion arrays is examined, considering tradeoffs between wave energy production and fishery profits and the value of the coastal viewshed. This analysis approximates wave energy siting for the coast of Oregon, and focuses on siting in the offshore dimension. While in reality, placement decisions will need to be made in a two-dimensional context, this cross-shore analysis provides a first approximation of some of the key service interactions. Specifically, wave energy devices are best anchored over sandy bottoms, which is also prime habitat and fishing grounds for Dungeness crab. Additionally, real estate value of coastal properties may be affected by the visual impact of wave energy devices. A simple model is used to examine the interactions among wave energy production, crab fishery profit, and impact to coastal real estate value from the altered viewscape, with respect to the offshore placement of a wave buoy array.

Design studies based on a single wave energy conversion (WEC) device generating $190 \mathrm{~kW}$ were used, suggesting that a target commercial wave power farm of $34 \mathrm{MW}$ would require 180 WEC devices arranged in an array extending $2 \mathrm{~km}$ cross-shelf and $9 \mathrm{~km}$ alongshore [79]. This amounts to about $4 \mathrm{MW} / \mathrm{km}$ of coastline. The 34-MW wave power array generates 300,000 MW h per year. If wave energy can be produced and sold at a profit of $\$ 0.01 /$ $\mathrm{kW} h$, this would amount to $\$ 3 \times 10^{6}$ per year per array. Dividing by the alongshore length of the array yields about $\$ 3 \times 10^{5}$ per year per alongshore $\mathrm{km}$. Wave energy conversion devices are not safe to deploy too close to shore where large winter waves could damage the devices and potentially uproot the array. Therefore, the assumption is made that WEC devices would not be placed shallower than the $30-\mathrm{m}$ isobath ( $3 \mathrm{~km}$ offshore for a $1 \%$ bottom slope). The expense of larger mooring elements and longer electrical transmission lines diminishes the profitability of wave power generation as water depth increases offshore. Thus, it is assumed the highest profitability occurs in a water depth of $50 \mathrm{~m}$ [80], which for the typical inner-shelf bottom slope off Oregon of $1 \%$, is found $5 \mathrm{~km}$ offshore. Profitability declines shoreward of this location, dropping to zero at $3 \mathrm{~km}$ and also declines toward the deep sea, dropping to zero at $10 \mathrm{~km}$ offshore (Fig. 3B and Table 1 ).

The annual revenue from the Oregon Dungeness crab fishery over the past decade ranges from $\$ 5$ million to $\$ 44$ million per year, based on fluctuations in harvest levels and market conditions (http://www.oregondungeness.org/fishery.shtml). Using the high value and dividing by the length of the Oregon coastline, about $440 \mathrm{~km}$ (admittedly an overestimate since about 10\% of the Oregon shelf is rocky bottom, which is not exploited by the crab fishery), this is $\$ 1 \times 10^{5}$ per alongshore kilometer of coastline per year. The high value of the crab fishery was used to represent potential value of the fishery. While not needed for the tradeoff analysis, one can estimate the number of crab pots needed to realize this catch value. Using an estimate of $\$ 1.43$ per crab, this amounts to $7.0 \times 10^{4}$ crabs per $\mathrm{km}$ per year. If it is assumed that during the four-month intensive crab fishing season, pots are turned around every 6 days and about 10 crabs are caught in each pot per soak, then the total crab catch would require about 350 pots per kilometer (i.e., 154,000 pots fished in Oregon waters), which is not an unrealistic number (http://www.oregondunge ness.org/fishery.shtml). In order to estimate the impact of displacing the crab fishery for a WEC array, it is necessary to know the cross-shelf distribution of pots. It is assumed that pots are placed no closer than the $30-\mathrm{m}$ isobath (3 $\mathrm{km}$ offshore) (an underestimate of how close to shore crabs are fished) and no deeper than the $90-\mathrm{m}$ isobath (9 km offshore) and that the optimum crab fishing depth is at the $60-\mathrm{m}$ isobath (6 km offshore) (Table 1) (http://www.oregondungeness.org/fishery.shtml). To estimate the impact on the crab fishery due to the presence of a wave energy installation, the loss of a 2-km cross-shelf swath - the width of the WEC array - is moved across the crab fishery profit curve from zero to $15 \mathrm{~km}$ offshore, resulting in the curve in Fig. 3A.

To model the effect of a wave farm on coastal real estate values via its alteration of the viewscape, it is assumed that a wave buoy is approximately $6 \mathrm{~m}$ in height and $4.5 \mathrm{~m}$ in width (e.g., Finavera Renewables, AquaBuOY) and the height of an observer is $5 \mathrm{~m}$ (height from a typical bluff). The wave buoy array is modeled as $9 \mathrm{~km}$ long perpendicular to the coast, with wave buoys evenly distributed across the $9 \mathrm{~km} \times 2 \mathrm{~km}$ array. In Oregon, the median value of a 1-acre cross-shore, 1-km along-shore parcel of coastal property (ca. 15 acres along the coast), with a median distribution of one residence structure per acre, is $\$ 21,000,000$ (using http:// www.rwre.com, the median was calculated based on 33 coastal properties with ocean views that listed the asking price and acreage, November 2008). To make this property value comparable to the fishery and energy annualized values, the property value (with an intact view) was multiplied by a discount rate of 

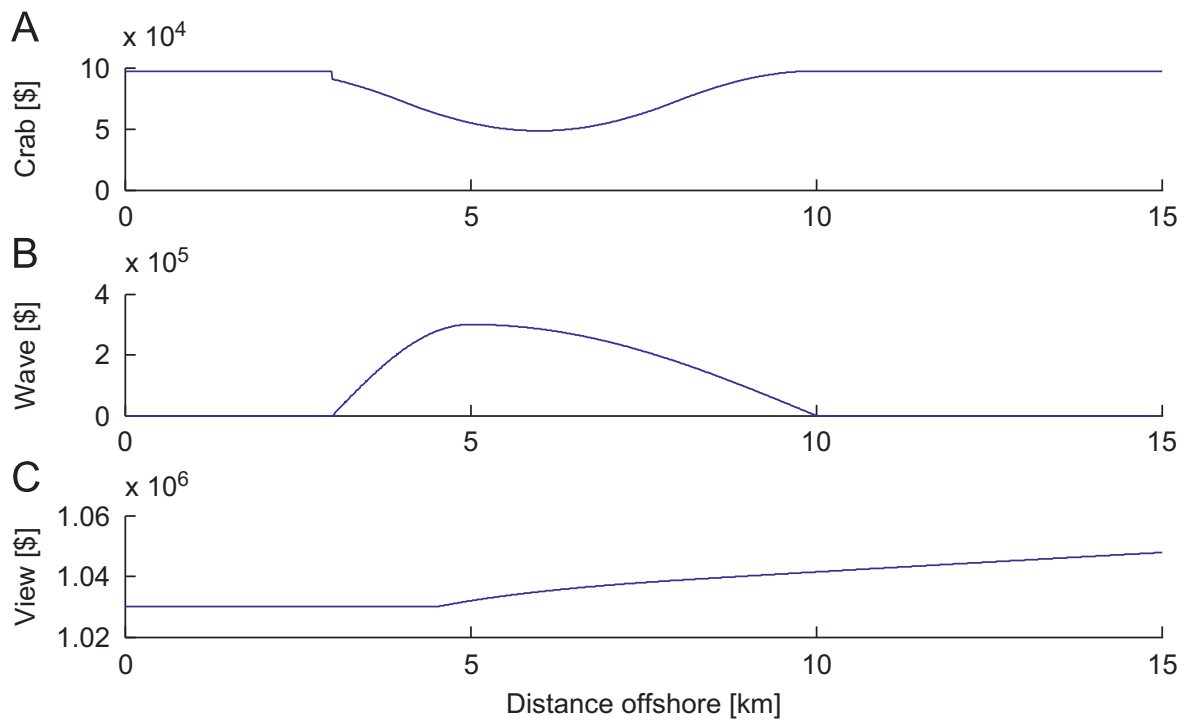

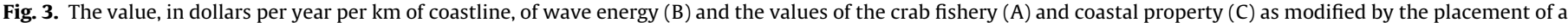
wave energy facility, with respect to the offshore placement of a wave energy facility.

Table 1

Functions used to model the three services in the wave energy case study.

\begin{tabular}{ll}
\hline Service & Functions \\
\hline Wave energy profit (WE) & WE $=0$ for $x<3 \mathrm{~km}$, \\
& $\mathrm{WE}=\$ 3 \times 10^{5} \sin [\pi(x-3 \mathrm{~km}) / 4 \mathrm{~km}]$ \\
& for $x \geq 3 \mathrm{~km}$ and $x<5 \mathrm{~km}$, \\
& WE $=\$ 3 \times 10^{5} \cos [\pi(x-5 \mathrm{~km}) / 10 \mathrm{~km}]$ \\
& for $x \geq 3 \mathrm{~km}$ and $x<5 \mathrm{~km}$, \\
& WE $=0$ for $x \geq 10 \mathrm{~km}$ \\
& $\mathrm{CF}=0$ for $x<3 \mathrm{~km}$, \\
& $\mathrm{CF}=\$ \sin [\pi(x-3 \mathrm{~km}) / 6 \mathrm{~km}]$ \\
Crab fishery profit (CF) & for $x \geq 3$ and $x<9$, \\
& $\mathrm{CF}=0$ for $x \geq 9 \mathrm{~km}$ \\
& VS $=\$ 2.1 \times 10^{7} \times \delta ; \delta=$ discousnt \\
& rate $=0.05$ \\
\hline
\end{tabular}

$5 \%$ to get the future value of the view in $\$ / \mathrm{km}$ through infinite time (Table 1). Finally, given that there is somewhat equivocal evidence regarding the effect of offshore wind or wave farms on aesthetics and property values [81-83], it was assumed that annualized property values were decreased by the proportion of the horizon view that is impacted. This proportion is calculated using simple geometry, based on the height of the observer, the height and width of the energy facility, and the distance of the facility offshore (from zero to $15 \mathrm{~km}$ offshore), taking into account the curvature of the earth and assuming that coastal properties have a 90 degree angle view of the ocean. Property values are reduced by $2 \%$ or less (Fig. $3 \mathrm{C}$ ).

The analysis reduces to a cost-benefit analysis because all three services are modeled in the same units $(\$ / \mathrm{km} / \mathrm{year})$; the values of the three services are summed to determine the optimal offshore placement for a WEC array, where total value is maximized (Fig. 4A). In cases where services are not valued in common units, the frontier can be determined from multidimensional tradeoff analysis. In this example, the frontier is complex with multiple inflection points (Fig. 4B). Considering all three services, the optimal placement of a wave energy facility is at $4.95 \mathrm{~km}$ offshore. This is only slightly inshore from where it would be sited without considering the other services $(5 \mathrm{~km})$. This can also be compared with the optimal siting considering wave energy and the crab fishery only $(4.93 \mathrm{~km})$ or wave energy and property value only $(5.12 \mathrm{~km})$. The value distribution of the crab fishery pushes the optimal placement of a wave facility closer to shore, while property value has the opposite effect.

Considering all three services, wave facility placement is minimally affected by the two other services because of the large dollar value of energy production relative to the other services and because of the opposing spatial effects of interactions with the other services. In some cases, as is shown here, tradeoff analysis may indicate that interactions that were presumed to be important are relatively insignificant, potentially ameliorating stakeholder conflicts. On the other hand, if other services had been examined or if these services had been valued in terms other than dollars, a different answer may have emerged.

\section{Conclusions}

This paper presents a straightforward, scientifically based approach for quantitatively evaluating tradeoffs among multiple ecosystem services. Acknowledgment of such tradeoffs is not new-managers and ecologists have long recognized the complex interactions between different human uses of ecosystems. However, there is a tendency for decisions about tradeoffs to be made implicitly, which is often exacerbated by fragmented or singlesector management, whereby each service is managed independently. An ecosystem service tradeoff approach reveals when the single-sector approach is appropriate and when there is a need for a more integrated, ecosystem-based approach. It also reveals suboptimal management decisions, with the potential for eliminating conflicts among user groups when a service or multiple services could be maintained or even increased without a cost to other services. Finally, this framework can also be used to evaluate when the frontier is unobtainable due to regulatory or legal constraints and could even be used to guide institutional changes to ensure more equitable service delivery.

While the simplicity of the approach as presented here makes it an ideal starting point for evaluating tradeoffs among ecosystem services, implementing the approach in practice is not without challenges. It is difficult to accurately estimate indifference curves (and in particular, define what is meant by "societal preference"), develop production functions, and identify appropriate ecosystem service metrics [84] given the diversity of human values, perceptions and preferences related to ocean uses 


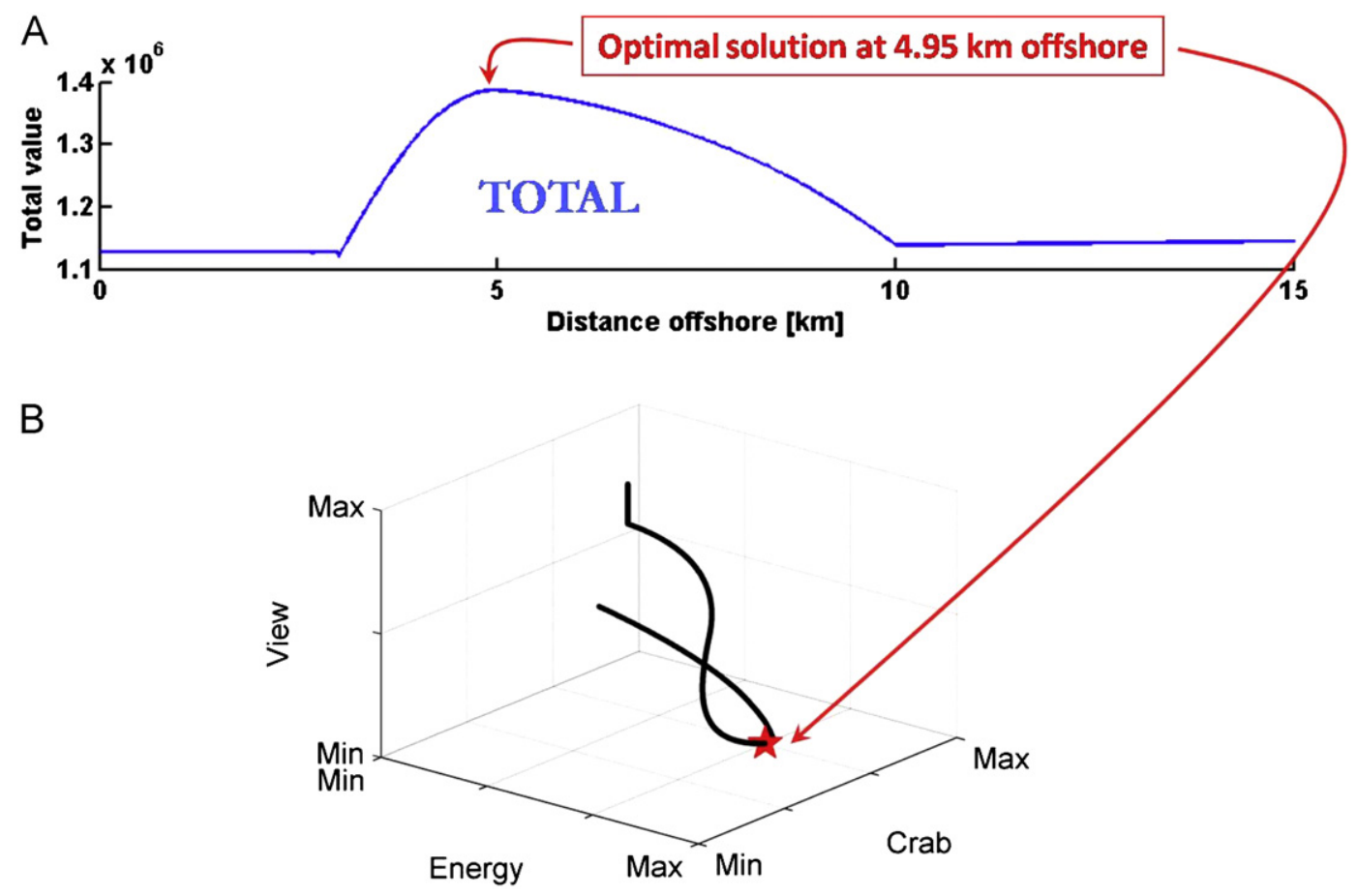

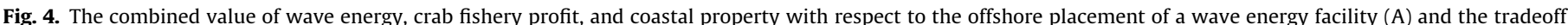

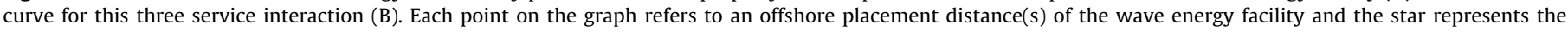

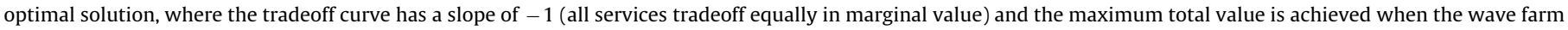
is sited $4.95 \mathrm{~km}$ from shore.

and the contention surrounding the valuation of non-market goods. Furthermore, it may often be difficult to identify and quantify all of the services and issues that should guide decision-making. These challenges are not entirely insurmountable, and added complexity will certainly be required to improve the applicability of this tool to real world management. For example, production functions and service interactions are not static over time. To consider temporal variability, efficiency frontiers can be assumed to have a dynamic path, rather than operating in steady state (e.g. [49]), with management decisions taking frontier trajectories into account. Additionally, our ability to distinguish among different types of service interactions depends on our level of certainty regarding how much of the services will be realized under different management policies. If uncertainty is high and the error bars around each point are large, it may be difficult to distinguish among frontier shapes. However, alternative frontiers can be analyzed in order to consider uncertainty from inputs, from external drivers, and for the effect of management actions. Historical data and past management "experiments" and associated outcomes can be used to learn more about the system. Ironically, management failures of the past may even prove beneficial in the long-term because of their contribution to reducing uncertainty.

The framework presented here has the potential to advance how marine spatial planning is conducted. Managers and scientists need simple and transparent means for determining the tradeoffs, or lack thereof, among key services and communicating these interactions to policy makers and stakeholders. This approach can be readily communicated, developed using complex simulation models, empirical data, or a conceptual understanding of the system, applied in a range of systems and to a variety of services and service metrics, and can be nested within other marine management approaches (e.g., Integrated Ecosystem Assessments [85]). Tradeoff analysis can also evaluate services that are not readily valued in monetary units, and can consider services measured in different units, allowing managers a quantitative approach for balancing services that otherwise would seem like apples and oranges. These attributes suggest that ecosystem service tradeoff analysis is likely to be a key ingredient in efforts to realize effective marine spatial planning in which existing and emerging ocean uses are explicitly planned for in a spatial context.

\section{Acknowledgments}

This work stemmed from the California Current EcosystemBased Management (CCEBM) initiative, facilitated by the Communication Partnership for Science and the Sea (COMPASS) and the University of California, Santa Cruz and funded by the David and Lucile Packard Foundation and the Gordon and Betty Moore Foundation. We thank the CCEBM Science Advisory Committee for helpful input and K. McLeod and several anonymous reviewers for comments on the manuscript. The marine reserve-fishery case study benefited from input from J. White, D. Siegel, J. Watson, and S. Mitarai. Additional support was provided by the Partnership for Interdisciplinary Studies for Coastal Oceans (PISCO; contribution number 420), the Paul G. Allen Family Foundation (S.D.G., C.C., S.E.L., C.W.), NSF Grants OCE-0527168 and OCE0453071 (J.A.B.), and a grant from the Packard Foundation to the National Center for Ecological Analysis and Synthesis (B.S.H.).

\section{References}

[1] MA. Ecosystems and human well being: a synthesis report based on the findings of the Millennium Ecosystem Assessment. Washington, DC: Island Press; 2005.

[2] USCOP. An ocean blueprint for the 21st century: final report of the US Commission on Ocean Policy. Washington, DC: US Commission on Ocean Policy [USCOP]; 2004. 
[3] POC. America's living oceans: charting a course for sea change. Arlington, VA: Pew Oceans Commission [POC]; 2003.

[4] McLeod KL, Lubchenco J, Palumbi SR, Rosenberg AA. Scientific consensus statement on marine ecosystem-based management. Washington DC: Communication Partnership for Science and the Sea; 2005.

[5] Rosenberg AA, McLeod KL. Implementing ecosystem-based approaches to management for the conservation of ecosystem services. Mar Ecol Prog Ser 2005;300:270-274.

[6] Grumbine RE. What is ecosystem management? Conserv Biol 1994;8:27-38.

[7] Christensen NL, Bartuska AM, Brown JH, Carpenter S, Dantonio C, Francis R, et al. The report of the ecological society of America committee on the scientific basis for ecosystem management. Ecol Appl 1996;6:665-691.

[8] McLeod KL, Leslie HM. Ecosystem-based management for the oceans. Washington, DC: Island Press; 2009.

[9] Ehler C, Douvere F. An international perspective on marine spatial planning initiatives. Environ J Interdiscip Stud 2011;37:9-20.

[10] Halpern BS, Diamond J, Gaines S, Gelcich S, Gleason M, Jennings S, et al. Near-term priorities for the science, policy and practice of Coastal and Marine Spatial Planning (CMSP). Mar Policy 2012;36:198-205.

[11] Douvere F, Ehler C. The role of marine spatial planning in implementing ecosystem-based, sea use management. Spec Issue Mar Policy 2008;32: 759-843.

[12] Lester SE, McLeod KL, Tallis HM, Ruckelshaus M, Halpern BS, Levin PS, et al. Science in support of ecosystem-based management for the US West Coast and beyond. Biol Conserv 2010;143:576-587.

[13] Costanza R, d'Arge R, de Groot R, Farber S, Grasso M, Hannon B, et al. The value of the world's ecosystem services and natural capital. Nature 1997;387:253-260.

[14] Brauman KA, Daily GC, Duarte TK, Mooney HA. The nature and value of ecosystem services: an overview highlighting hydrologic services. Annu Rev Environ Resour 2007;32:67-98.

[15] Barbier EB, Koch EW, Silliman BR, Hacker SD, Wolanski E, Primavera J, et al. Coastal ecosystem-based management with nonlinear ecological functions and values. Science 2008;319:321-323.

[16] Koch EW, Barbier EB, Silliman BR, Reed DJ, Perillo GME, Hacker SD, et al. Non-linearity in ecosystem services: temporal and spatial variability in coastal protection. Front Ecol Environ 2009;7:29-37.

[17] Raudsepp-Hearne C, Peterson GD, Bennett EM. Ecosystem service bundles for analyzing tradeoffs in diverse landscapes. Proc Natl Acad Sci USA 2010;107:5242-5247.

[18] Halpern BS, McLeod KL, Rosenberg AA, Crowder LB. Managing for cumulative impacts in ecosystem-based management through ocean zoning. Ocean Coastal Manage 2008;51:203-211.

[19] Tallis H, Kareiva P, Marvier M, Chang A. An ecosystem services framework to support both practical conservation and economic development. Proc Nat Acad Sci USA 2008;105:9457-9464.

[20] Heal GM, Barbier EB, Boyle KJ, Covich AP, Gloss SP, Hershner CH, et al. Valuing ecosystem services: toward better environmental decision-making. Washington, DC: The National Academies Press; 2004.

[21] Rodriguez JP, Beard TD, Bennett EM, Cumming GS, Cork SJ, Agard J, et al. Trade-offs across space, time, and ecosystem services. Ecol Soc 2006:11.

[22] Halpern BS, Walbridge S, Selkoe KA, Kappel CV, Micheli F, D’Agrosa C, et al. A global map of human impact on marine ecosystems. Science 2008;319: 948-952.

[23] Worm B, Barbier EB, Beaumont N, Duffy JE, Folke C, Halpern BS, et al. Impacts of biodiversity loss on ocean ecosystem services. Science 2006;314:787-790.

[24] MA. Marine and coastal ecosystems and human well-being: a synthesis report based on the findings of the Millennium Ecosystem Assessment. Nairobi, Kenya: United Nations Environment Programme; 2006.

[25] Grafton RQ, Arnason R, Bjorndal T, Campbell D, Campbell HF, Clark CW, et al. Incentive-based approaches to sustainable fisheries. Can J Fish Aquat Sci 2006;63:699-710.

[26] Costello C, Gaines SD, Lynham J. Can catch shares prevent fisheries collapse? Science 2008;321:1678-1681.

[27] Crowder LB, Osherenko G, Young OR, Airame S, Norse EA, Baron N, et al. Resolving mismatches in US ocean governance. Science 2006;313:617-618.

[28] Juda L. The European union and ocean use management: the marine strategy and the maritime policy. Ocean Dev Int Law 2007;38:259-282.

[29] Mas-Colell A, Whinston MD, Green JR. Microeconomic theory. New York: Oxford University Press; 1995.

[30] Markowitz H. Portfolio selection. J Finance 1952;7:77-91.

[31] Halpern BS, White C, Lester SE, Costello C, Gaines SD. Using portfolio theory to assess tradeoffs between return from natural capital and social equity across space. Biol Conserv 2011;144:1499-1507.

[32] Sanchirico JN, Smith MD, Lipton DW. An empirical approach to ecosystembased fishery management. Ecol Econom 2008;64:586-596.

[33] Keeney RL, Raiffa H. Decisions with multiple objectives: preferences and value tradeoffs. New York: John Wiley \& Sons, Inc; 1976.

[34] Brown K, Adger WN, Tompkins E, Bacon P, Shim D, Young K. Trade-off analysis for marine protected area management. Ecol Econom 2001;37: 417-434.

[35] Martinet V, Blanchard F. Fishery externalities and biodiversity: trade-offs between the viability of shrimp trawling and the conservation of Frigatebirds in French Guiana. Ecol Econom 2009;68:2960-2968.
[36] Pascoe S, Bustarnante R, Wilcox C, Gibbs M. Spatial fisheries management: a framework for multi-objective qualitative assessment. Ocean Coastal Manage 2009;52:130-138.

[37] Bevacqua D, Melia P, Crivelli AJ, Gatto M, De Leo GA. Multi-objective assessment of conservation measures for the European eel (Anguilla anguilla): an application to the Camargue lagoons. ICES J Mar Sci 2007:64:1483-1490.

[38] Daily GC, Polasky S, Goldstein J, Kareiva PM, Mooney HA, Pejchar L, et al. Ecosystem services in decision making: time to deliver. Front Ecol Environ 2009;7:21-28.

[39] Nelson E, Mendoza G, Regetz J, Polasky S, Tallis H, Cameron D, et al. Modeling multiple ecosystem services, biodiversity conservation, commodity production, and tradeoffs at landscape scales. Front Ecol Environ 2009;7:4-11.

[40] Sanchirico J, Mumby P. Mapping ecosystem functions to the valuation of ecosystem services: implications of species-habitat associations for coastal land-use decisions. Theor Ecol 2009;2:67-77.

[41] Guerry A, Ruckelshaus M, Arkema K, Bernhardt J, Guannel G, Kim, C., et al. Balancing benefits from nature: using ecosystem services as the currency for coastal and marine spatial planning. Int J Biodivers Ecosyst Serv Manage http://dx.doi.org/10.1080/21513732.2011.647835, in press.

[42] Varian HR. Intermediate microeconomics: a modern approach. 7th edW.W. Norton; 2005

[43] Barbier EB. Valuing ecosystem services as productive inputs. Econ Policy 2007;49:178-229.

[44] Daily GC, Matson PA. Ecosystem services: from theory to implementation. Proc Natl Acad Sci USA 2008;105:9455-9456.

[45] Tallis H, Polasky S. Mapping and valuing ecosystem services as an approach for conservation and natural-resource management. Ann N Y Acad Sci 2009;1162:265-283.

[46] Chee YE. An ecological perspective on the valuation of ecosystem services. Biol Conserv 2004:120:549-565.

[47] Nelson E, Polasky S, Lewis DJ, Plantinga AJ, Lonsdorf E, White D, et al. Efficiency of incentives to jointly increase carbon sequestration and species conservation on a landscape. Proc Natl Acad Sci USA 2008;105:9471-9476.

[48] Polasky S, Nelson E, Camm J, Csuti B, Fackler P, Lonsdorf E, et al. Where to put things? Spatial land management to sustain biodiversity and economic returns Biol Conserv 2008;141:1505-1524.

[49] Nalle DJ, Montgomery CA, Arthur JL, Polasky S, Schumaker NH. Modeling joint production of wildlife and timber. J Environ Econ Manage 2004;48: 997-1017.

[50] Wossink A, Swinton SM. Jointness in production and farmers' willingness to supply non-marketed ecosystem services. Ecol Econom 2007;64:297-304.

[51] Naidoo R, Ricketts T. Mapping the economic costs and benefits of conservation. PLoS Biol 2006;4:e360.

[52] Myers RA, Worm B. Rapid worldwide depletion of predatory fish communities. Nature 2003;423:280-283.

[53] Roberts CM, Hawkins JP, Gell FR. The role of marine reserves in achieving sustainable fisheries. Philos Trans Roy Soc B: Biol Sci 2005;360:123-132.

[54] Palumbi SR. Marine reserves: a tool for ecosystem management and conservation. Arlington, VA: Pew Oceans Commission; 2002.

[55] Halpern BS. The impact of marine reserves: do reserves work and does reserve size matter? Ecol Appl 2003;13:S117-S137.

[56] Lester SE, Halpern BS, Grorud-Colvert K, Lubchenco J, Ruttenberg B, Gaines $\mathrm{SD}$, et al. Biological effects within no-take marine reserves: a global synthesis. Mar Ecol Prog Ser 2009;384:33-46.

[57] Klein CJ, Steinback C, Watts M, Scholz AJ, Possingham HP. Spatial marine zoning for fisheries and conservation. Front Ecol Environ 2009;8:349-353.

[58] McCook LJ, Ayling T, Cappo M, Choat JH, Evans RDs, De Freitas DM, et al. Adaptive management and monitoring of the Great Barrier Reef reserve network: A globally signficant case study in marine conservation. Proc Nat Acad Sci USA 2010;107:18278-19285.

[59] Gaylord B, Gaines SD, Siegel DA, Carr MH. Marine reserves exploit population structure and life history in potentially improving fisheries yields. Ecol Appl 2005;15:2180-2191.

[60] Kellner JB, Nisbet RM, Gaines SD. Spillover from marine reserves related to mechanisms of population regulation. Theor Ecol 2008;1:117-127.

[61] White C, Kendall BE, Gaines S, Siegel DA, Costello C. Marine reserve effects on fishery profit. Ecol Lett 2008;11:370-379.

[62] Costello C, Polasky S. Optimal harvesting of stochastic spatial resources. ] Environ Econ Manage 2008;56:1-18.

[63] Sanchirico JN, Malvadkar U, Hastings A, Wilen JE. When are no-take zones an economically optimal fishery management strategy? Ecol Appl 2006:16:1643-1659.

[64] Costello C, Rassweiler A, Siegel D, Micheli F, De Leo G, Rosenberg AA. The value of spatial information in MPA network design. Proc Natl Acad Sci USA 2010;107:18294-18299.

[65] Halpern BS, Lester SE, Kellner JB. Spillover from marine reserves and the replenishment of fished stocks. Environ Conserv 2010;36:268-276.

[66] White C, SelkoeK A, Watson J, Siegel DA, Zacherl DC, Toonen RJ. Ocean currents helps explain population genetic structure. Proc Roy Soc B: Biol Sci 2010;277:1685-1694.

[67] White JW, Caselle JE. Scale dependent changes in the importance of larval supply and habitat to abundance of a reef fish. Ecology 2008;89:1323-1333.

[68] Haidvogel DB, Arango H, Budgell WP, Cornuelle BD, Curchitser E, Lorenzo ED et al. Ocean forecasting in terrain-following coordinates: formulation and skill assessment of the Regional Ocean Modeling System. J Comput Phys 2008;227:3595-3624. 
[69] Mitarai S, Siegel DA, Winters KB. A numerical study of stochastic larval settlement in the California Current system. J Mar Syst 2008;69:295-309.

[70] Rassweiler, A, Costello, C, Siegel, DA. Marine protected areas and the value of spatially optimized fishery management. Proc Natl Acad Sci USA, in press.

[71] WCGA. Final action plan for the West Coast Governors' Agreement on ocean health. Washington, Oregon and California: The Office of the Governors; 2008 $\langle$ http://westcoastoceans.gov/documents/〉.

[72] EC. Energy 2020: a strategy for competitive, sustainable and secure energy. Communication from the Commission to the European Parliament, the Council, the European Economic and Social Committee and the Committee of the Regions. Brussels: European Commission [EC]; 2010.

[73] Thorpe T. A brief review of wave energy: a report produced for the UK Department of Trade and Industry. AEA Technology plc; 1999 p. 2000.

[74] Pelc R, Fujita RM. Renewable energy from the ocean. Mar Policy 2002;26:471-479.

[75] Gill AB. Offshore renewable energy: ecological implications of generating electricity in the coastal zone. J Appl Ecol 2005;42:605-615.

[76] Callaway E. To catch a wave (News Feature). Nature 2007;450:156-159.

[77] Boehlert GW, McMurray GR, Tortorici CE. Ecological effects of wave energy in the Pacific Northwest. U.S. Dept Commerce, NOAA Tech Memo NMFS-F/SPO92; 2008. p. 174.
[78] Scruggs J, Jacob P. Harvesting ocean wave energy. Science 2009;323: 1176-1178.

[79] Previsic, M, Begard, R, Hagerman, G, Siddiqui, O. System level designs, performance and costs-Oregon state offshore wave power plant. Global Energy Partners, LLC; 2004. Available online at <http://oceanenergy.epri. com/attachments/wave/reports/006_Oregon_System_Level_Design_RB_1129-04.pdf $>$.

[80] Previsic, M, Begard, R, Hagerman, G. E2I EPRI assessment: offshore wave energy conversion devices. Global Energy Parnters, LLC; 2004. Available online at 〈http://oceanenergy.epri.com/attachments/wave/reports/004_WEC_Device_ Assess_Report_Rev1_MP_6-16-04.pdf $\rangle$.

[81] Firestone J, Kempton W. Public opinion about large offshore wind power: underlying factors. Energy Policy 2007;35:1584-1598.

[82] Kempton W, Firestone J, Lilley J, Rouleau T, Whitaker P. The offshore wind power debate: views from Cape Cod. Coast Manage 2005;33:119-149.

[83] Bishop ID. Determination of thresholds of visual impact: the case of wind turbines. Environ Plan B: Plan Design 2002;29:707-718.

[84] Tallis H, Lester SE, Ruckelshaus M, Plummer M, McLeod KL, Guerry A, et al. New metrics for managing and sustaining the ocean's bounty. Mar Policy 2011;36:303-306.

[85] Levin PS, Fogarty MJ, Murawski SA, Fluharty D. Integrated ecosystem assessments. Public Libr Sci Biol 2009; 7:e1000014. 